\title{
SOME EFFECTS OF A KETOGENIC DIET
}

BY

\author{
RICHARD W. B. ELLIS, M.A., M.D.
}

(From the Children's Department, Westminster Hospital, London).

The following study is based on the administration of a ketogenic diet to twenty children between the ages of three and eight years, the majority of cases being chosen with the purpose of testing tolerance to a high fat diet in various conditions. The diet employed, the details of which are given below, was found with slight modification for age to be sufficient to produce a marked ketosis in two to three days in most cases ; where it was ineffective in four days, the added factor of restricted fluid intake was employed. A positive ferric chloride test in the urine was taken as the criterion of an adequate ketosis, since Rothera's test is too sensitive to be of equal value.

Post-anæesthetic vomiting.-The first point investigated was the effect of ketosis on post-anæsthetic vomiting. It is well known that starvation, and hence vomiting, will produce ketosis in the human subject ; the point at issue was whether ketosis, however produced, would in the post-anæsthetic state be likely to result in excessive vomiting.

A preliminary comparison was made between two groups each of seven children who were subjected to tonsillectomy. It was not possible to keep the experimental condition exactly uniform for each child as regards operation and anæsthetic, but the former consisted of tonsillectomy by dissection in each case, and the anæsthetics employed were ethyl chloride for induction followed by ether.

The first group was prepared before operation by the administration of large amounts of carbohydrate, given principally in the form of barley sugar. It was usually possible to give a full half pound of barley sugar on the morning of operation, thus ensuring a high glycogen content of the liver at the time of the anæsthetic. The second group was given no food by mouth on the day of operation. The urine of each patient was tested at six, ten, and twelve hours after operation, and the amount of vomiting noted. As would be expected, the second group all showed ketone bodies in considerable amount in the 10 and 12 hour urines, whilst in the first group ketosis was slight or absent. Two of the first group showed glycosuria in the 6 hour specimen. With regard to the vomiting, every child regurgitated a small amount of bloody vomitus when coming out of the anæsthetic. This was regarded as normal. In only one case was there excessive vomiting ; this was in a child in the second (unprepared) group, who showed twelve hours after operation very marked ketonuria, a strong smell of acetone in the breath, hyperpnœa, and a blood sugar of $\cdot 056$ 
per cent. He vomited four times. In none of the other cases was it possible to demonstrate any appreciable difference in post-anæsthetic discomfort, vomiting, or time of recovery.

It appeared, therefore, that a considerable post-anæsthetic ketosis could exist without necessarily giving rise to vomiting, and it was decided to investigate the effect of an induced ketosis in this respect.

For this purpose two patients were put on a ketogenic diet for four days before operation, and had developed a positive ferric chloride reaction in the urine by that time. Two other patients, who had not been prepared with carbohydrate before operation and who had developed a moderate ketosis, were started on a high fat diet (including cream and cod-liver oil) immediately they were able to take food by mouth after tonsillectomy, and were thus kept with a continuous ketonuria for 5 to 6 days after operation. The subjects were all between 6 and 8 years. In no case was there more than the single bloody vomitus previously described, or complaint of nausea or headache.

Cyclical vomiting.-Although the relationship of ketosis to cyclical vomiting has been already investigated by Findlay ${ }^{1}$ and others, opportunity was taken of studying the effect of a ketogenic diet in two typical cases which came under observation. The first was a particularly severe one.

J.H., female, aged $4 \mathrm{yr}$. Patient had had recurrent attacks of vomiting since infancy, usually lasting $1-3$ days and thought to be precipitated by 'chills.' In Nov., 1930, she was admitted to Westminster Hospital with 6 days history of continued and intractable vomiting with increasing drowsiness. The vomitus had become brown and grumous, with subsequently small amounts of bright blood. The stools showed presence of considerable occult blood. Vomitus for three days in hospital contained much dark blood. Very marked ketonuria. Diffuse tenderness in epigastrium. T. $101^{\circ}$. Patient given rectal and subcutaneous saline, intravenous glucose, and blood transfusion. Fluids gradually retained by mouth. Alcohol test meal two weeks after admission showed complete absence of free $\mathrm{HCl}$; repeated two weeks later, $\mathrm{HCl}$ present in normal amount. Discharged after five weeks free from symptoms. Readmitted to hospital in Feb., 1931, with less severe attack of vomiting, rapidly yielding to treatment, and with low grade pyrexia. Ketonuria persisted 5-6 days after vomiting ceased.

The second patient was a boy of six years who had had recurrent 'bilious attacks' for 2 to 3 years. He had enlarged infected tonsils which were removed during his stay in hospital.

Both children were of the nervous, rather precocious type.

To both patients, when free of symptoms, a ketogenic diet was given by gradually increasing the ketogenic ratio from that of the ward diet. Both children rapidly developed and retained a marked ketosis. In neither was there any nausea, vomiting, or other evidence of intolerance. In fact the first subject (J.H.) took the diet with more relish than any of the children treated, and used to lick the melted butter off the plate. She was also one of the very few who gained weight on the diet at first, though this gain ceased when the full ratio had been established.

It appears, therefore, that although in the established vomiting attack it is rational therapy to reduce the existing ketosis by glucose administration (taking care to give chlorides at the same time to replace those lost in the vomitus), a ketosis per se is not necessarily sufficient to precipitate an attack. There must be some other factor-either of nervous, infective, or toxic originwhich is primarily responsible. 
Convulsions.-Two patients with epileptiform seizures of the type described by Paterson and Bray ${ }^{2}$ were admitted with one or more convulsions occurring at the onset of an acute infection, associated with marked ketosis and a positive Rothera's test in the cerebrospinal fluid. When free from infection, both were given a ketogenic diet. In both cases the establishment of ketosis was well tolerated and was unassociated with any disturbance of the central nervous system, although the cerebrospinal fluid again showed a positive Rothera's test.

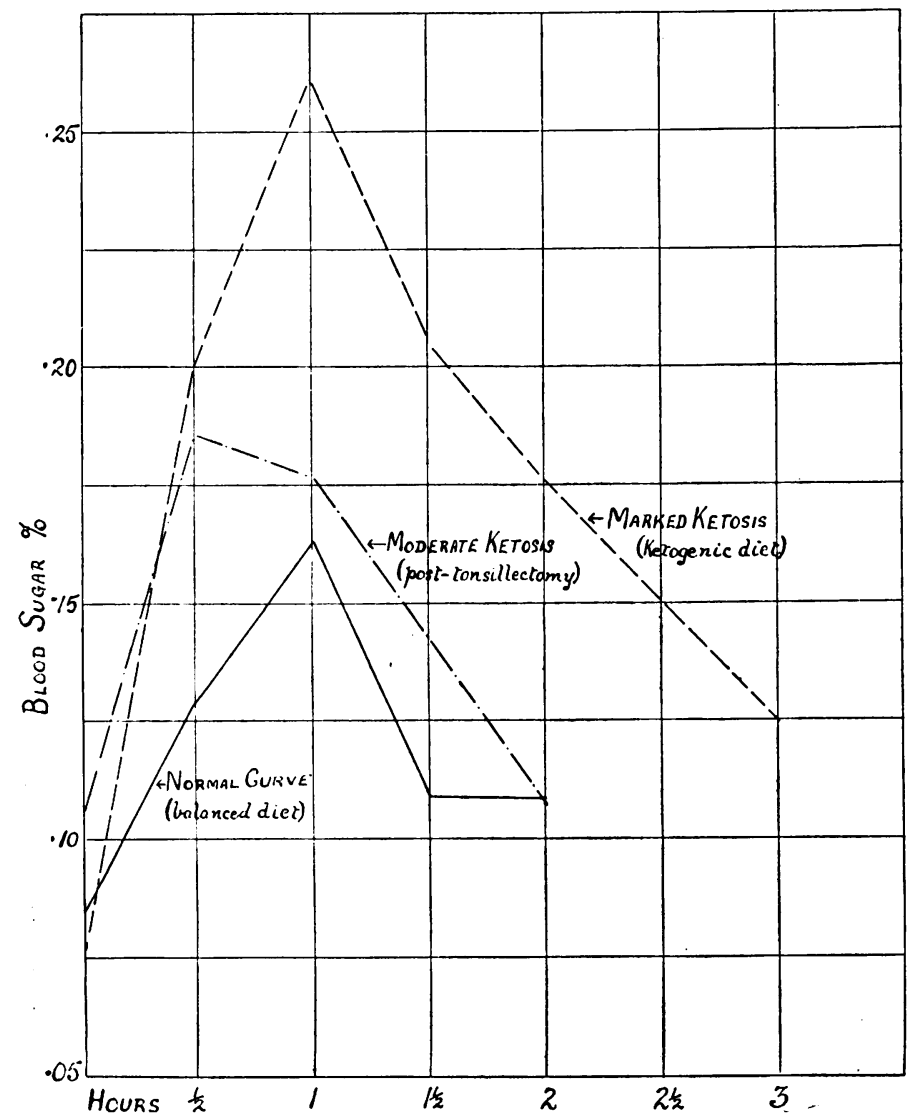

Fig. 1. Effect of ketosis on the blood sugar curve. L. R., weight $36 \mathrm{lb}$. Age 6 years. 20 grm. glucose in $50 \mathrm{c} \mathrm{cm}$. water.

Carbohydrate metabolism.-Southwood ${ }^{3}$, and subsequently several other authors, found that in the patient adapted to the metabolism of fat (and in whom the liver was presumably infiltrated with this substance) considerable interference with carbohydrate storage occurred. A somewhat similar observation was made by Tallerman ${ }^{4}$, using the lævulose tolerance test, in the case of children showing ketosis in the course of infections. In five children in the present series this loss of carbohydrate tolerance on a ketogenic diet was investigated by means of the glucose tolerance test (using MacLean's 
method of blood sugar estimation). This test was carried out in the morning, no food having been taken for 12 hours previously. It was found that in each case marked ketosis was associated with an abnormal blood-sugar curve. The typical disturbance is illustrated in Fig. 1.

In this subject (a female child of six who developed ketosis with some difficulty) the normal curve obtained on a well-balanced diet shows a rise in blood sugar from a fasting level of $\cdot 085$ per cent. to a maximum of $\cdot 162$ per cent. an hour after glucose had been given by mouth. When this point is reached, the mechanism for the removal of sugar from the blood is called into play and the blood sugar falls rapidly to reach normal levels within two hours. At no point is the renal threshold for sugar reached (approximately $\cdot 180$ per cent.) so that no sugar is passed in the urine. In the curve obtained during

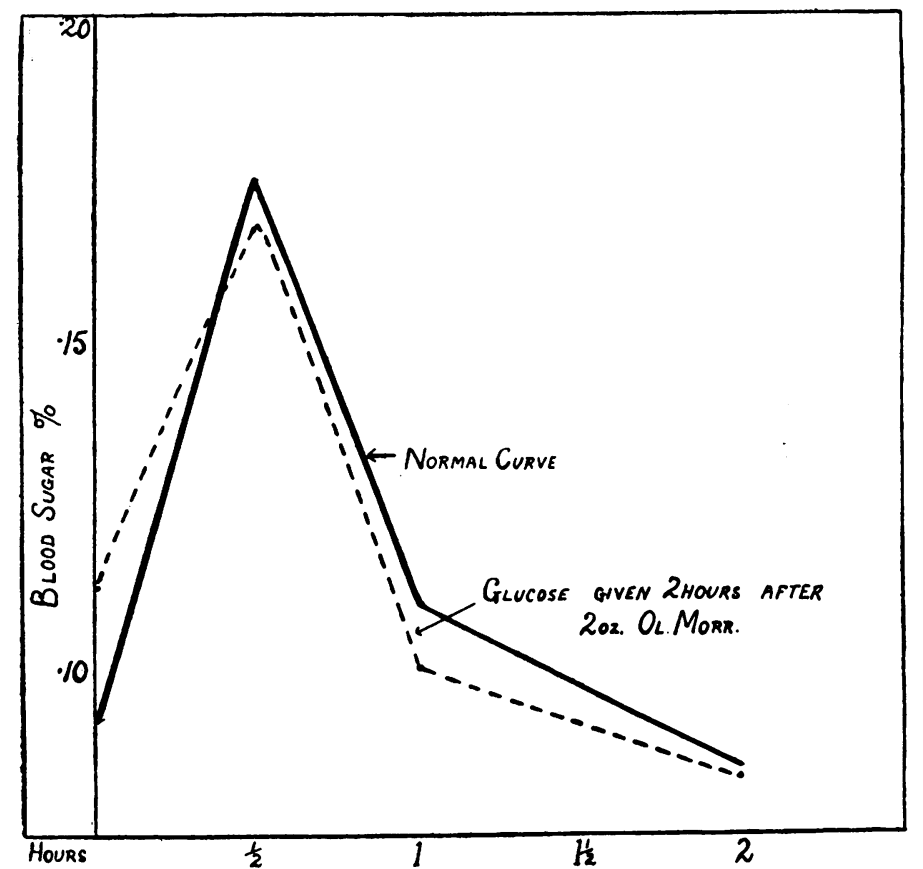

Fig. 2. Effect of $2 \mathrm{oz}$. of cod-liver oil on glucose tolerance test. D. S., weight $60 \mathrm{lb}$. Age $8 \frac{1}{2}$ years. $30 \mathrm{grm}$. glucose in $60 \mathrm{c.cm}$. water.

marked ketosis, however, it will be seen that the blood sugar not only rises to a much higher level ( $\cdot 266$ per cent.) but also falls more slowly, being still much elevated at the end of two hours. During the greater part of this period the blood sugar was above the threshold value, with the result that sugar appeared in considerable quantity in the urine. The third curve was obtained during a period of moderate ketosis (Rothera test + , ferric chloride test + ) 12 hours after tonsillectomy, where ketosis is principally due to starvation. Here again there is evidence of carbohydrate intolerance (an abnormally high curve). Slight glycosuria occurred; the blood sugar rose above the threshold value but for a much shorter period than during marked ketosis. It is most probable 
that there is no essential difference between the intolerance developed on a ketogenic diet and that during starvation. In the first case the liver is concerned with the metabolism of exogenous fat taken by mouth, and in the latter with endogenous fat that has been previously stored. In neither case can the liver rapidly readjust to the storage and metabolism of carbohydrate.

Fig. 2 shows the normal curve and the curve obtained when glucose was administered two hours after $2 \mathrm{oz}$. of cod-liver oil in a boy of $8 \frac{1}{2}$ years. It was found that this dose of oil was insufficient in this subject to produce ketosis, i.e., was within the limits of what the liver could normally metabolize, and it is

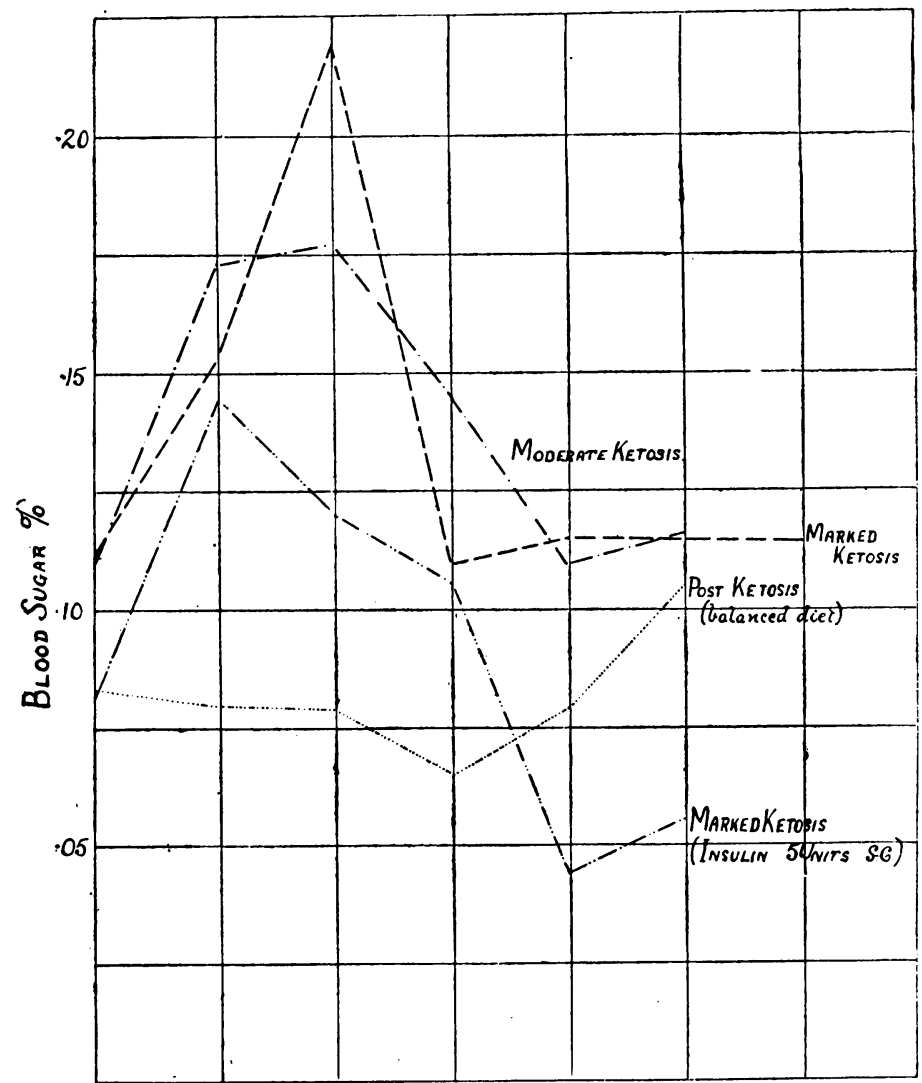

Fic. 3. Effect of ketogenic diet and insulin on the blood sugar curve. E. A., weight $35 \mathrm{lb}$. Age $3 \frac{1}{2}$ years $20 \mathrm{grm}$. glucose in $50 \mathrm{c.cm}$. water.

clear from a comparison of the two curves that it had no appreciable effect on the glucose tolerance. Although the full dose of fat was probably not completely absorbed by the time the tolerance test was carried out, the latter would suggest that intolerance to carbohydrate only occurs when the liver's normal ability to metabolize fat has been overtaxed.

Fig. 3 illustrates the same point in a third subject, the intolerance during a mild ketosis being definitely less marked than during a more severe ketosis. It will also be seen that the subcutaneous administration of 5 units of insulin at the time the glucose was given by mouth was sufficient to return the ketosis 
curve to normal or subnormal levels. It might be argued that this return to normal is evidence that the intolerance is due to inhibition of insulin secretion in the organism on a high fat diet, but we have found that in the starving adult subject a readjustment of the blood-sugar curve following glucose and insulin administration is not necessarily associated with a rise in R.Q. such as would be expected if carbohydrate were being normally metabolized.

The post-ketosis curve (obtained four days after discontinuance of the ketogenic diet) shows an exceptionally high tolerance, there being no rise in

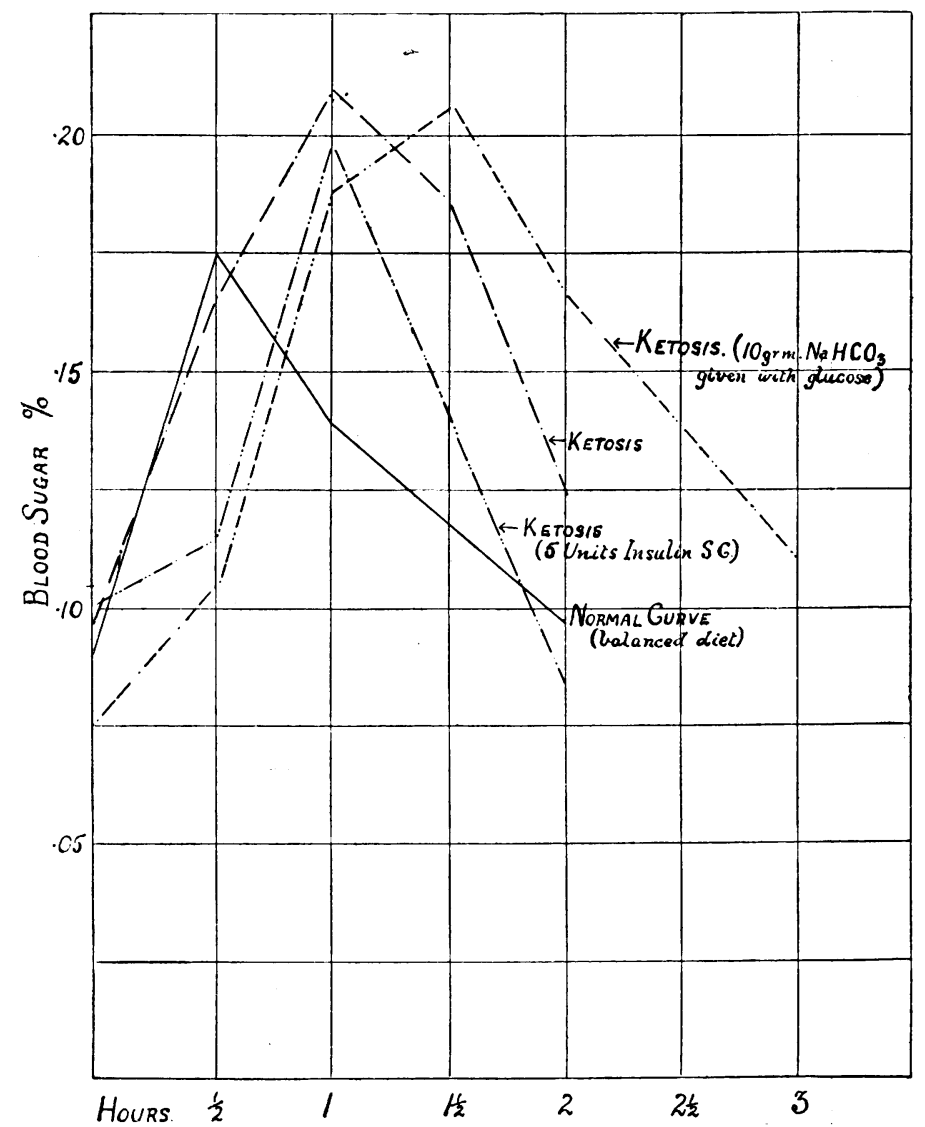

Frc. 4. Effects of ketogenic diet, insulin and alkali on the blood sugar curve. W. H., weight $4 \mathrm{~J} \mathrm{lb.} \mathrm{Age} 6.20 \mathrm{grm}$. glucose in $50 \mathrm{c.cm}$. water.

blood sugar one hour after glucose administration. A similar finding was described by Kaguera ${ }^{5}$ and by Kohn and others ${ }^{6}$. It has been suggested that the cause is either over-secretion of insulin or an increased call for sugar by the glycogen depots which have become emptied during the ketogenic period.

Fig. 4 shows a similar carbohydrate intolerance during ketosis in a fourth subject in whom the ferric chloride test never became strongly positive. The return toward normal with 5 units of insulin is not here as dramatic as in the previous case, but it is probable that if the insulin had been given rather earlier (so that its maximum action would have corresponded with the maximum 
rise in blood sugar) the threshold would not have been passed. In this caso the curve was repeated during ketosis giving $10 \mathrm{grm} . \mathrm{NaHCO}_{3}$ at the same time as the glucose, a dose of alkali amply sufficient to counteract any tendency there might be toward an acidosis. It is clear that it resulted in no increase in tolerance, the effect being rather to produce a slower rise and more delayed fall in blood sugar. This shows that the deficient tolerance cannot reasonably be attributed to an acidosis, but is more probably due to the inability of the cells which are concerned with the metabolism of fat to readjust rapidly to the metabolism of carbohydrate.

General effects.- It was found that there was considerable variation in the ease with which different subjects developed ketosis, probably depending on the ease with which the individual could store fat. The majority of subjects

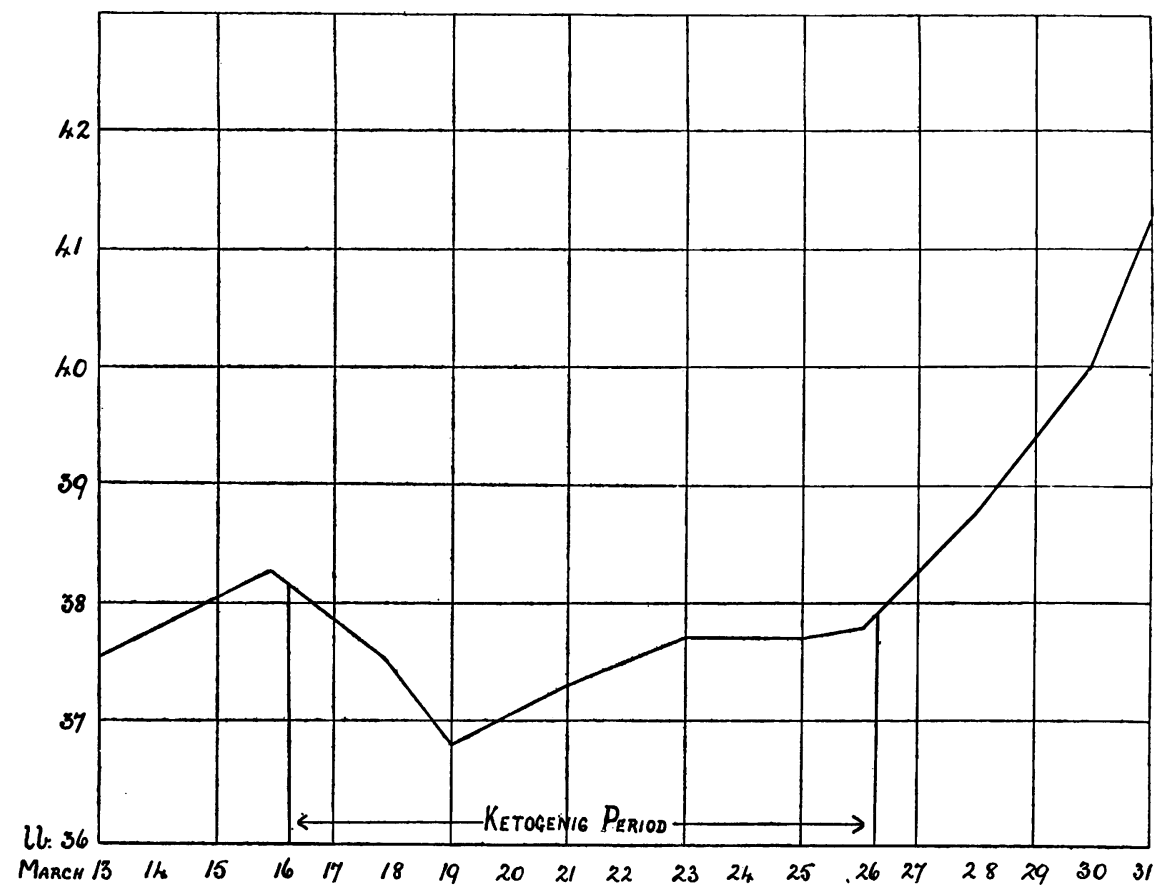

FIG. 5. Effect of ketogenic diet on body weight. W. H., age 6 : post-empyema.

took the diet well for a week or ten days but became tired of it at the end of that time. In three pyrexial cases in which it was given (two post-empyema and one post-mastoid) the diet was taken well without nausea. Of the apyrexial cases nausea and coated tongue were noted in one case only.

The effect of the diet on the weight curve was striking. In all cases except two the weight fell or remained stationary throughout the ketogenic period, in spite of the fact that the caloric intake was considerably in excess of that when on the ordinary ward diet. In only two cases was fluid intake restricted, and salt was given in normal amount.

Fig. 5 shows the typical effect on the weight, the return to a balanced diet being followed by a rapid gain, 
Ketogenic diet employed. -8 a.m. Olive oil $\frac{1}{2}$ oz. Ol. Mor. $3 \mathrm{drm}$. Fried fish or sardines 2 oz. Top milk 6 oz. Bran bišuits ad lib. 1 slice white bread. Butter 1 oz.

12.30 p.m. Mineed beef 3 oz. Cabbage 2 oz. Butter 1 oz. Olive oil $\frac{1}{2}$ oz. Ol. Mor. 3 drm. Top rice pudding $1 \mathrm{oz}$.

4.30 p.m. Fat ham or bxcon 2 oz. Butter 1 oz. Top milk 6 oz. Olive oil $\frac{1}{2}$ oz. Ol. Mor. 3 drm. Bran biscuits ad lib.

\section{Summary and conclusions.}

1. In two groups of children subjected to tonsillectomy it was found that considerable post-anæsthetic ketosis could exist without necessarily causing vomiting or other symptoms.

2. Artificially produced ketosis before and after operation was well tolerated.

3. In two casas of cyclical vomiting and in two patients who had had convulsions at the onset of an acuts infection, a ketogenic diet produced no symptoms.

4. The intolerance to carbohydrate produced by a high ketogenic diet was investigated by means of the glucose tolerance test. While insulin tended to readjust the blood sugar curve to normal, sodium bicarbonate had no effect in lessaning the intolerance.

5. The majority of patients showed a loss of weight or failure to gain weight during the ketogenic period.

6. It is not claimed that ketosis can never be reponsible for clinical disturbances, since in extreme degrees considerable change in acid-base equilibrium may take place. It is, however, suggested that a considerable ketosis may be well tolerated by many children, including certain 'cyclical vomiters' and normal children undergoing operation. It follows that a disg:osis of 'ketosis' as an explanation of symptoms should only be made with the greatest caution and when every other possible caus has been excluded. This is of additional importance when it is remembered that prolonged administration of glucose in considerable quantity may result in precipitation of diabetes in a subject in whom pancreatic function is defective.

I wish to express my sincere thanks to Dr. Donald Paterson for his help and encouragement, and for permission to publish particulars of patients under his care ; and to Dr. W. M. Goldblatt for much advice and criticism. The work was carried out during the tenure of a Wander Research Scholarship at the Westminster Hospital.

\section{REFERENCES.}

1. Findlay, L., Arch. Dis. Childh., Lond., 1930, V, 293.

2. Paterson D., \& Bray, G., Ibid., 1929, IV, 138.

3. Southwood, A. R., Med. J. Austral., Sydney, 1923, II, 460.

4. Tallerman, K., Am. J. Dis. Child., Chicago, 1925, XXX, 467.

5. Kaguera, N., J. Biochem., Tokyo, 1922, I, 333.

6. Kohn, J. L., Fries, M. E., \& Felshin, G., Am, J. Dis. Child., Chicag̊o, 1927, XXXIV, 857. 